\title{
Hygrothermic performance of the exterior and interior surfaces of buildings
}

\author{
H. Stopp \& P. Strangfeld \\ Department of Building Physics, \\ University of Applied Sciences FH Lausitz, Cottbus, Germany
}

\begin{abstract}
One of the current tasks of building physics is to find solutions in sense of the sustainability. That means we must save heating energy and raw materials. Therefore we have to develop building envelope parts with innovative characteristics. This paper shows the coupled heat and moisture transfer at adjacent areas of surfaces of the envelope parts of buildings. In this context the interaction of the external and internal surfaces of the building with the outdoor and indoor climate components are demonstrated. Longwave emission and shortwave absorption, driving rain and evaporation cooling on the outside and the adsorption-desorption processes of humidity of the room air inside must be considered in the management of passive air conditioning to create a permissible indoor climate in winter and summer periods. A good modelling of the coupled heat and mass transfer and a validated software play an important role; including knowing the material parameters of the structures. Results of experimental investigation and numerical simulation are discussed with regard to the infrared reflexion of coatings, fluctuation of the relative humidity in the rooms and the problems of mould and algae growth on the surfaces of the inside and outside walls. A mixture of phase change materials combined with hygroscopic bulk materials within envelop parts of buildings will be a solution for an energy saving passive air conditioning in the future .
\end{abstract}

Keywords: infrared reflection, energy saving, hygroscopicity, evaporation cooling, indoor climate, numerical simulation.

\section{Introduction}

In the past the maintenance of the building envelopes and the protection of the construction were the most important consideration. Nowadays, the energy 
balance and hygrothermal performance including microbiolocical growth on the facades of buildings and the attack of mould on interior surfaces of rooms are two of the current topics.

The general trend is to save heating energy [1] and raw materials. In this context it is not enough to improve the thermal insulation of outside walls, roofs and so on. We have to consider the envelope parts as an element of a reactive surface. It is necessary to prefer a climate-adequate building as opposed to building an adequate air condition. For instance this means the surfaces of buildings should be activated by plasters, renderings, coatings or paints and wallpapers with new effects. This paper deals with the coupled heat and moisture transfer at adjacent area of surfaces of envelopes influenced by the indoor and oudoor climate processes.

In the case of interior surfaces, the interest in hygroscopic properties of the paintings and coatings including phase changing materials is growing. By means of numerical simulation and laboratory work, this paper demonstrates the influence of internal surfaces of walls on the room climate. Problems concerning the regulation of the relative humidity in rooms by means of modulated sorption isotherms are investigated using calculation and experimental methods [2]. Different mixtures are tested, involving admixtures to increase the porosity and hygroscopic performance.

The hygrothermic of exterior surfaces requires the investigation of dewing and driving rain in connection with shortwave and longwave radiation. The influence of evaporation cooling on the energy transfer in wintertime and during the warm season is dependent on the hygric parameters of the coating of ouside walls. The effect of so-called energy efficient coatings and the exchange of radiation with the environment is measured in situ by means of a teststand.

\section{Outside surfaces of the external envelopes}

\subsection{Numerical simulation}

At first the magnitude of the hygrothermal effects should be estimated by means of numerical simulation of the coupled heat and mass transfer [3], an excellent backing of experimental work. It is carried out under condition of the climate boundary conditions of Middle Europe at the envelope parts of buildings applying the test reference year TRY West, Essen/ Germany.

\subsubsection{Effect of energy efficient coatings}

Figures 1-3 show the influence of the infrared reflection and the reduction of the evaporation cooling by special paints on the heat transmission of an outside wall, represented by the so called U-value. The emission coefficient $\varepsilon$ of the longwave radiation is varied from 1.0 up to 0.0 . The water repellent surfaces are characterized by an assumed water uptake value less than $10^{-4} \mathrm{~kg} / \mathrm{m}^{2} \mathrm{~h}^{1 / 2}$. The value of about $3 \mathrm{~kg} / \mathrm{m}^{2} \mathrm{~h}^{1 / 2}$ characterizes a usual surface. 


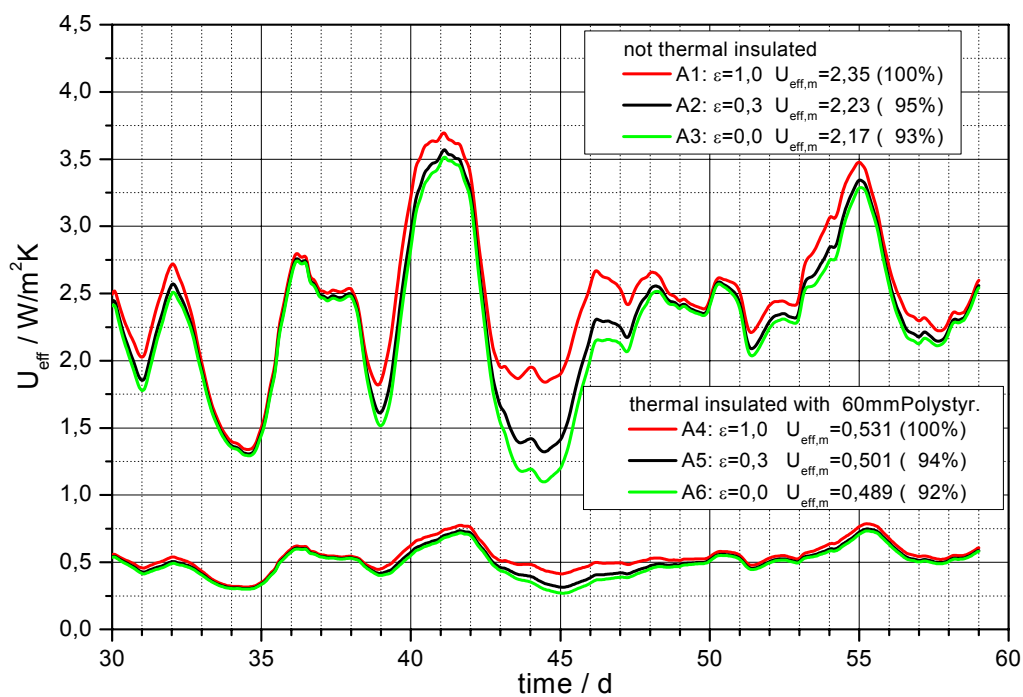

Figure 1: Course of the heat transmission coefficient "U-value eff" in the month of February calculated under climate conditions of Middle Europe for concrete wall structures (thickness: concrete $120 \mathrm{~mm}$, ETICS $60 \mathrm{~mm}$ polystyrene, north directed).

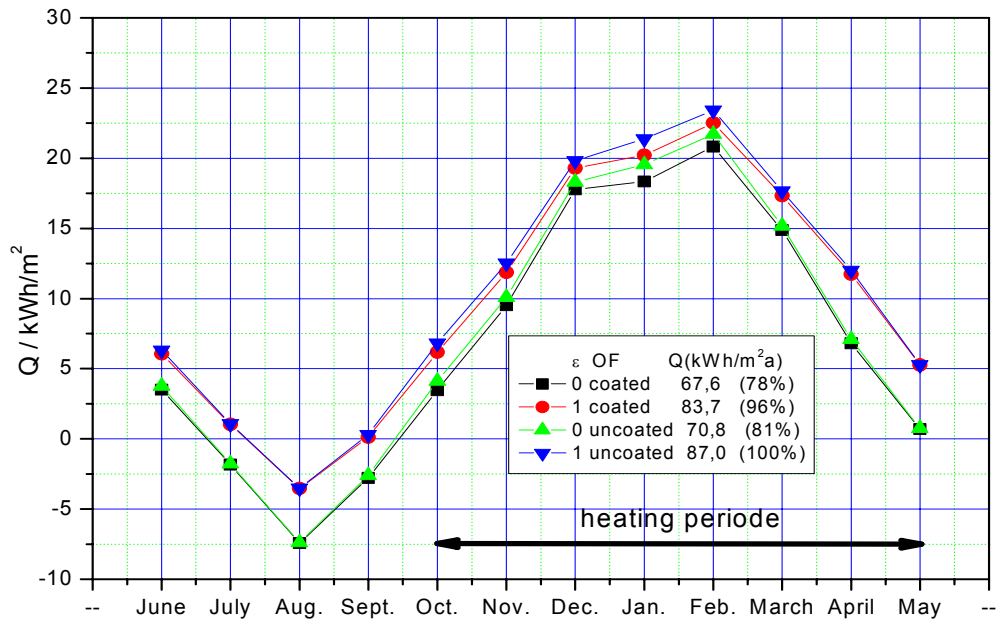

Figure 2: Monthly heat transmission coefficient "U-value" for a non thermally insulated, non water repellent masonry wall directed to the north, calculated under climate conditions of TRY Middle Europe in the lowlands. 


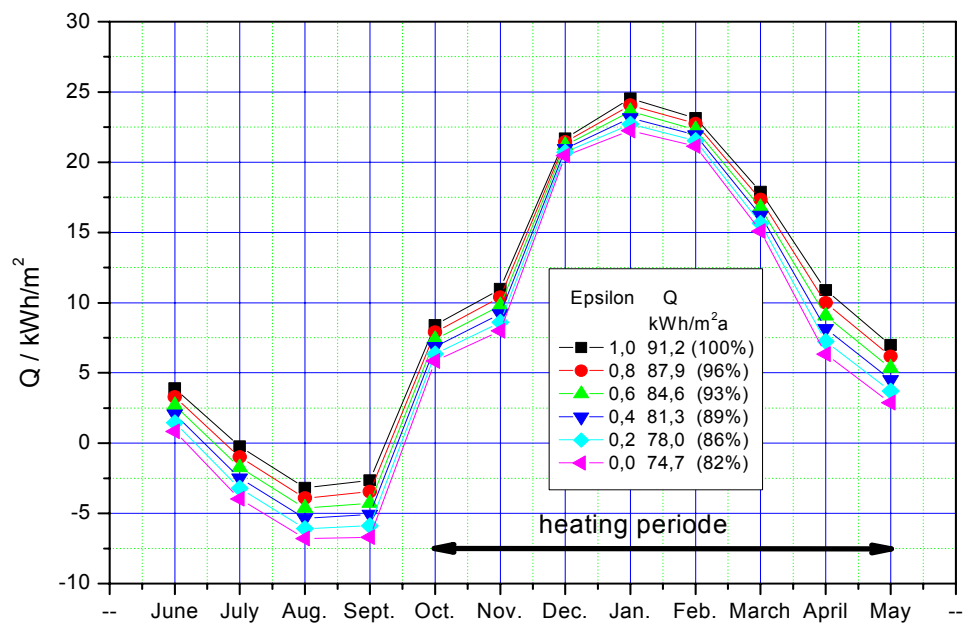

Figure 3: Monthly heat transmission coefficient "U-value" for a non thermally insulated, water repellent masonry wall directed to the north, calculated under climate conditions of TRY Middle Europe in the highlands.

\subsubsection{Avoidance of the microbiological growth}

2.1.2.1 Passive methods The moisture content of a structure, caused by dew and driving rain is one of the most important preconditions for microbiological growth [4]. Figure 4 represents the overhygroscopic moisture content dependant on the different hygrothermical properties (infrared reflection, heat capacity, water repellent) of the external surface of an outside wall.

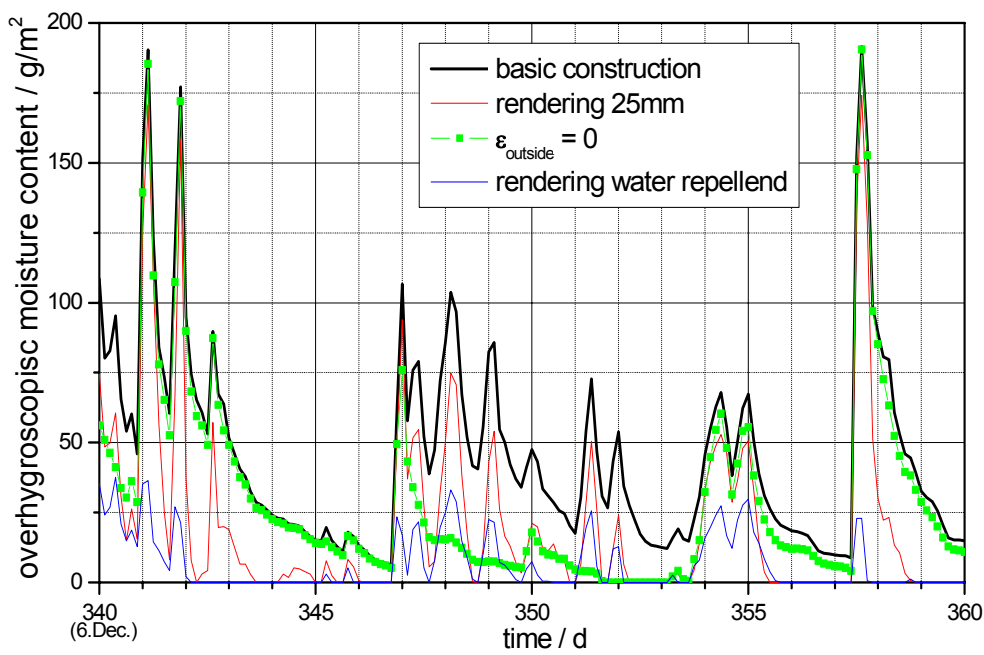

Figure 4: Time behaviour of the overhygroscopic moisture near the outside surface area of a mid thermally insulated $(60 \mathrm{~mm}$ polystyrene) concrete wall structure with a total thickness of $240 \mathrm{~mm}$. 
2.1.2.2 Heated surfaces Currently an option is investigated to avoid microbiological growth on outside walls by the reduction of the moisture content characterized by the dosis of dewing D [5]:

$$
D=\int_{1 . J a n}^{31 . D e c}\left(\vartheta_{\text {Dew }}-\vartheta_{\text {Surfac }}\right) * t \text { in } K h / a
$$

The reduction shall be reached by means of additional heating of the surface. The reference structure is a classic (non thermally insulated) outer wall free of microbiological growth $(\mathrm{D}=8.8 \mathrm{Kh} / \mathrm{a})$. The required heating energy dependant on the climate boundary conditions (balance of the longwave radiation, shortwave radiation and rel. humidity of the outdoor climate) is at least $12 \mathrm{kWh} / \mathrm{m}^{2}$.a [5].

\subsection{Measuring results}

The effect of so-called energy efficient paints in comparison with different usual surfaces is investigated by means of modified hot plate apparatures, special experiments with balls within a climate test cabinet and in situ measurements. All the results concerning a saving of heating energy are proved wrong [5]. Results of in situ measurements are represented in fig. 5.

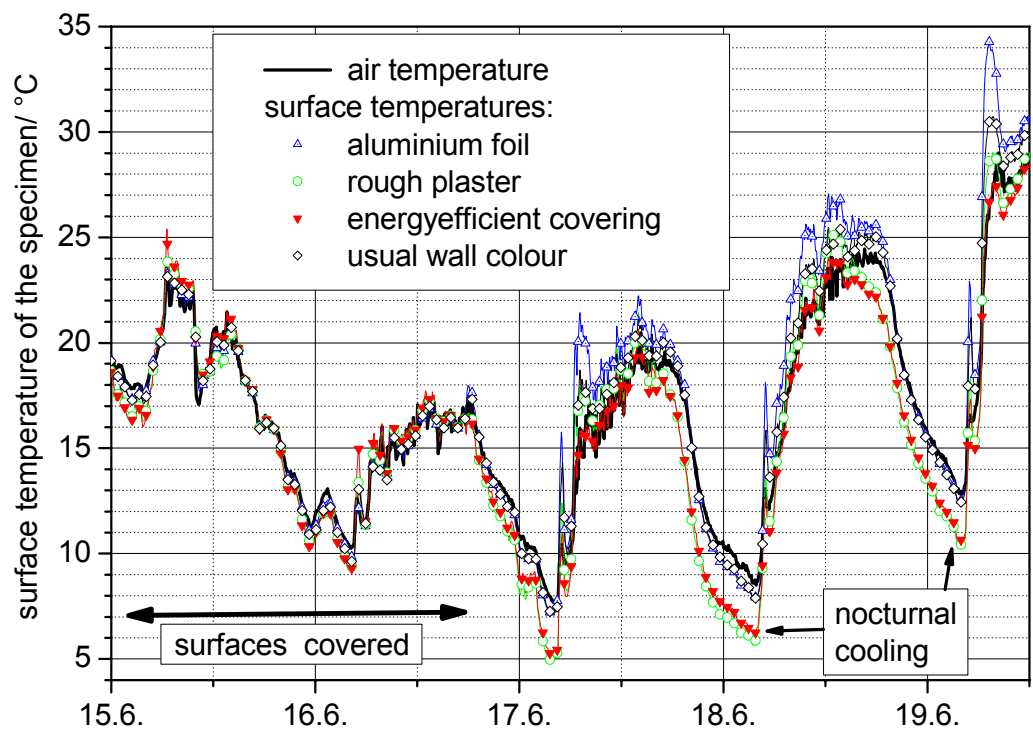

Figure 5: Investigation of the effect of so called energy efficient paints by means of a teststand; surfaces of the specimen directed to the north. 


\section{Interior wall surfaces}

\subsection{Calculation and numerical simulation}

\subsubsection{Analysis}

An analytical solution for the sorption of the water vapour will be found on the condition, that the course of the sorption isotherm is linear or constant. Formula (2) describes the absorbed hygroscopic moisture $\mathrm{m}(\mathrm{t})$ per area unit dependant on time, if there is a jump in the relative humidity of the air $\left(\varphi_{\text {air }}-\varphi_{\text {wall,surface }}\right)$.

$$
\begin{aligned}
& \frac{\mathrm{m}(\mathrm{t})}{\mathrm{A}}=\mathrm{p}_{\mathrm{S}} \cdot\left(\varphi_{\text {air }}-\varphi_{\text {wall,surface }}\right) \cdot \\
& \left\{\frac{2 \sqrt{\mathrm{t} \cdot \mathrm{b}_{\mathrm{D}}}}{\sqrt{\pi}}-\frac{\delta_{\mathrm{L}} \cdot \rho_{\mathrm{W}} \cdot \mathrm{w}_{\mathrm{h}}}{\mu \cdot \beta \cdot \mathrm{p}_{\mathrm{S}}}\left[1-\mathrm{e}^{\left(\frac{\mu \cdot \beta}{\delta_{\mathrm{L}}}\right)^{2} \cdot \mathrm{a}_{\mathrm{D}} \cdot \mathrm{t}} \cdot\left(\operatorname{erfd}\left(\frac{\mu \cdot \beta}{\delta_{\mathrm{L}}} \cdot \sqrt{\mathrm{a}_{\mathrm{D}} \cdot \mathrm{t}}\right)\right)\right]\right\} \\
& \mathrm{a}_{\mathrm{D}}=\frac{\delta_{\mathrm{L}}}{\mu} \cdot \frac{\mathrm{p}_{\mathrm{S}}}{\rho_{\mathrm{W}} \cdot \mathrm{w}_{\mathrm{h}}} \quad \mathrm{b}_{\mathrm{D}}=\sqrt{\frac{\delta_{\mathrm{L}}}{\mu} \cdot \frac{\rho_{\mathrm{W}} \cdot \mathrm{w}_{\mathrm{h}}}{\mathrm{p}_{\mathrm{S}}}} \quad \delta_{\mathrm{L}} \approx 1,85 \cdot 10^{-10} \mathrm{~s}
\end{aligned}
$$

\begin{tabular}{|l|l|l|l|}
\hline$\delta_{\mathrm{L}}$ & $\begin{array}{l}\text { coefficent of the diffusion } \\
\text { conductivity of the water } \\
\text { pressure }\end{array}$ & $\mathrm{w}_{\mathrm{h}}$ & max. hygroscopic moisture \\
\hline$\beta$ & $\begin{array}{l}\text { mass transfer coefficent of the } \\
\text { water pressure }\end{array}$ & $\mu$ & $\begin{array}{l}\text { number for the resistance of the } \\
\text { water vapour diffusion }\end{array}$ \\
\hline $\mathrm{b}_{\mathrm{D}}$ & $\begin{array}{l}\text { penetration coefficent of the } \\
\text { diffusion of the water pressure }\end{array}$ & $\mathrm{p}_{\mathrm{S}}$ & $\begin{array}{l}\text { saturation pressure of the water } \\
\text { vapour }\end{array}$ \\
\hline$\rho_{\mathrm{W}}$ & density of water & $\varphi$ & relative humidity \\
\hline
\end{tabular}

There is a simplified solution in case of

$$
\begin{aligned}
& \text { if } \quad t>t_{K} ; \quad t_{K}=30 \cdot \frac{\delta_{L} \cdot \rho_{\mathrm{W}} \cdot w_{h}}{\mu \cdot \beta^{2} \cdot p_{S}} \\
& \frac{m(t)}{A}=p_{S} \cdot\left(\varphi_{\text {air }}-\varphi_{\text {wall,surface }}\right) \cdot\left(\frac{2 \cdot b_{D} \cdot \sqrt{t}}{\sqrt{\pi}}-\frac{\delta_{L} \cdot \rho_{W} \cdot w_{h}}{\mu \cdot \beta \cdot p_{S}}\right)
\end{aligned}
$$

\subsubsection{Numerical simulation}

Fig. 6-9 describe the influence of the hygroscopicity on the course of the relative humidity in the magazine of an archive. For these buildings, for rooms without windows and no source of moisture by people the annual fluctuations are interesting [6]. 


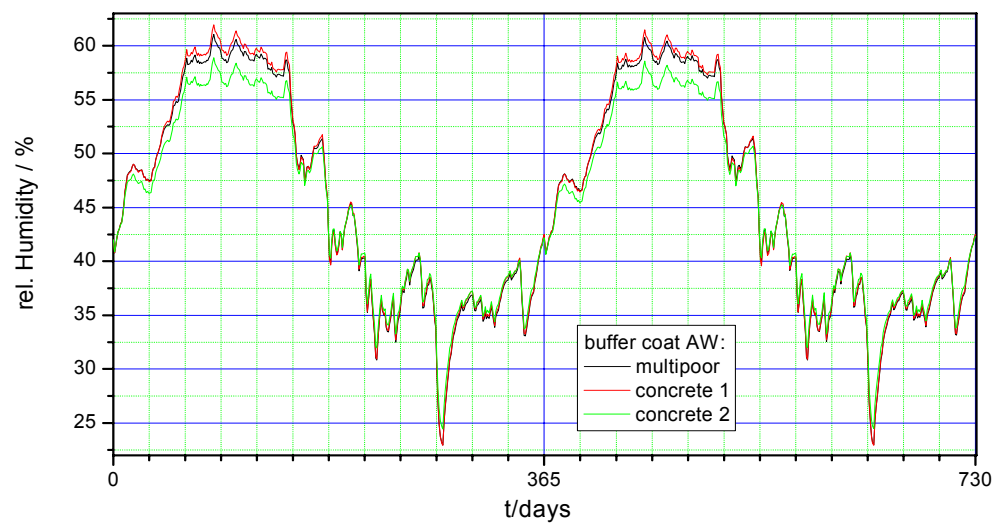

Figure 6: Annual indoor humidity in a magazine room $\left(\mathrm{V}=2360 \mathrm{~m}^{3}\right.$, if absolute humidity $\mathrm{x}_{\mathrm{i}}<\mathrm{x}_{\mathrm{a}}: \mathrm{n}=0,02 \mathrm{~h}^{-1}$, if $\mathrm{x}_{\mathrm{i}}>\mathrm{x}_{\mathrm{a}}: \mathrm{n}=0,1 \mathrm{~h}^{-1}$ ); exterior walls AW $\left(260 \mathrm{~m}^{2}\right)$ of different interior surfaces, with $20 \mathrm{~cm}$ buffer coat; the other surfaces: not hygroscopic.

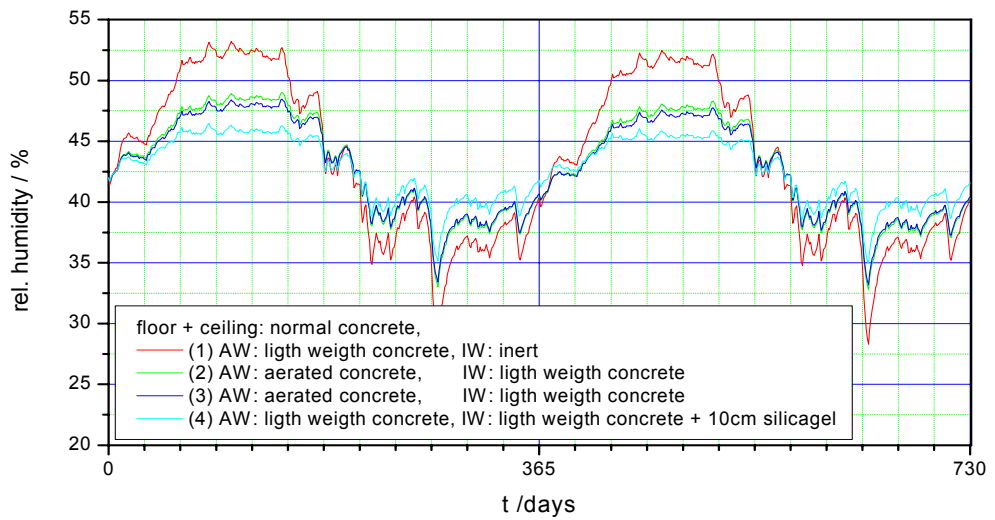

Figure 7: Annual indoor humidity in the magazine; exterior walls $\mathrm{AW}\left(260 \mathrm{~m}^{2}\right)$ of different interior surfaces, interior walls IW $\left(1012 \mathrm{~m}^{2}\right)$, ceiling $\left(1090 \mathrm{~m}^{2}\right)$ and floor FB $\left(1090 \mathrm{~m}^{2}\right)$ of different surfaces; case $4 \mathrm{FB}$ with $10 \mathrm{~cm}$ additional silica-gel fill (with regard to the air change rate $\mathrm{n}$ : see fig. 6 ). 


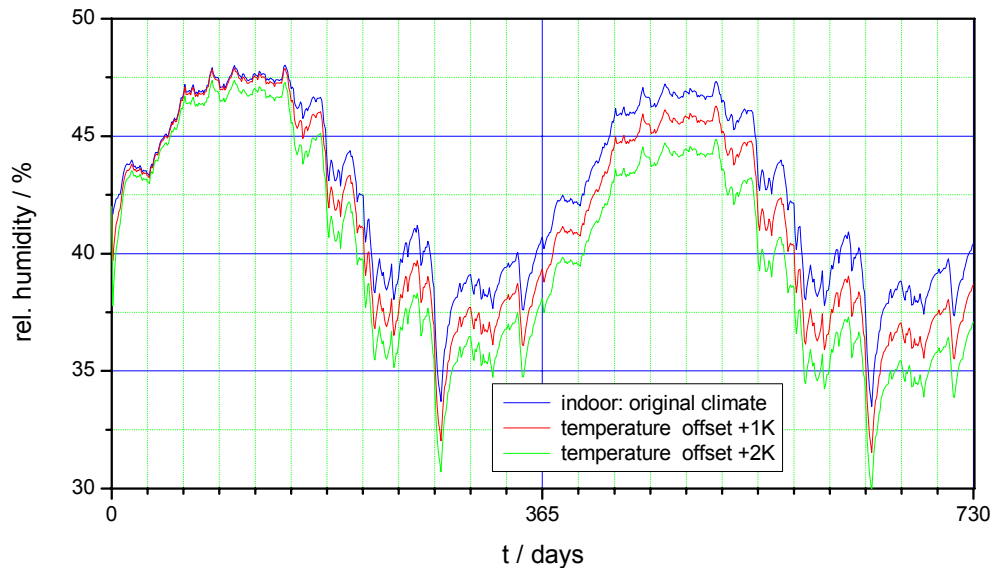

Figure 8: Annual indoor humidity in the magazine; exterior walls AW, interior walls IW, ceiling and floor FB of hygrocopic active surfaces according to case 3 of fig. 7 , with indoor air temperature values increased by 1 or $2 \mathrm{~K}$ (data: see figs. 6,7 ).

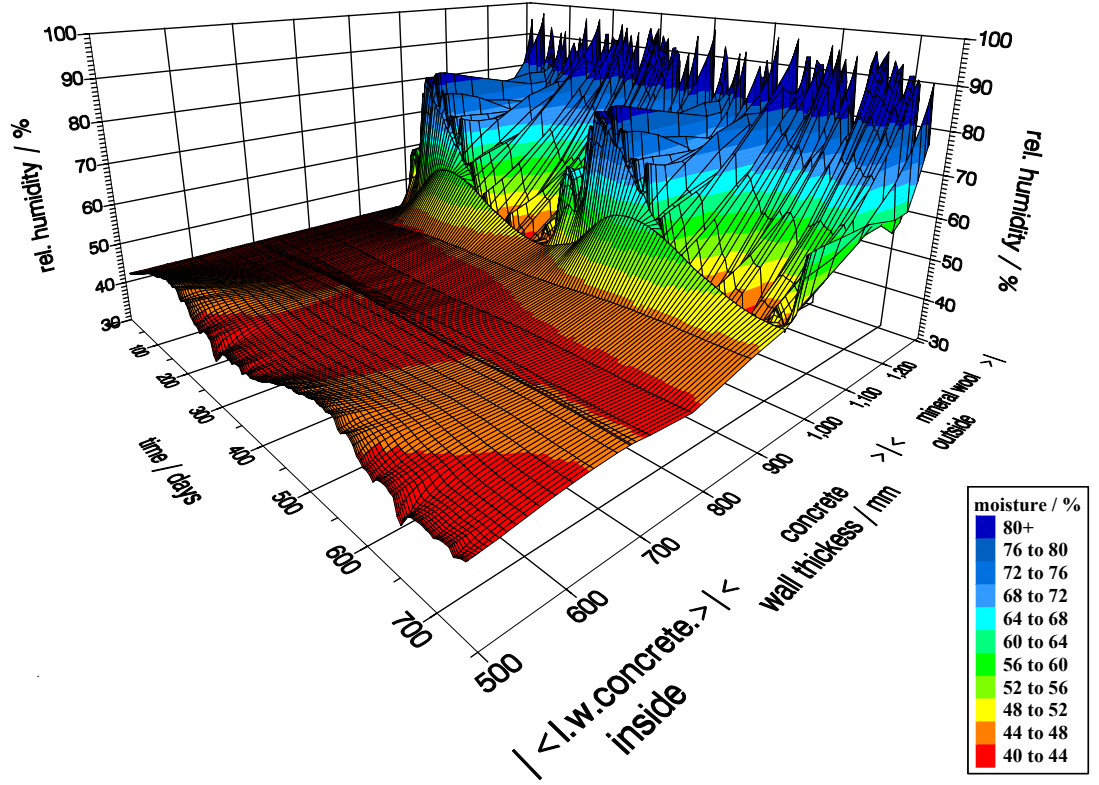

Figure 9: Course of the humidity in the air voids of the exterior wall $(20 \mathrm{~cm}$ lightweight concrete, $30 \mathrm{~cm}$ reinforced concrete, $30 \mathrm{~cm}$ mineral wool, venting). Interior walls: lightweight concrete, ceilings and floors: normal concrete (data: see figs. 6,7). 


\subsection{Measuring results}

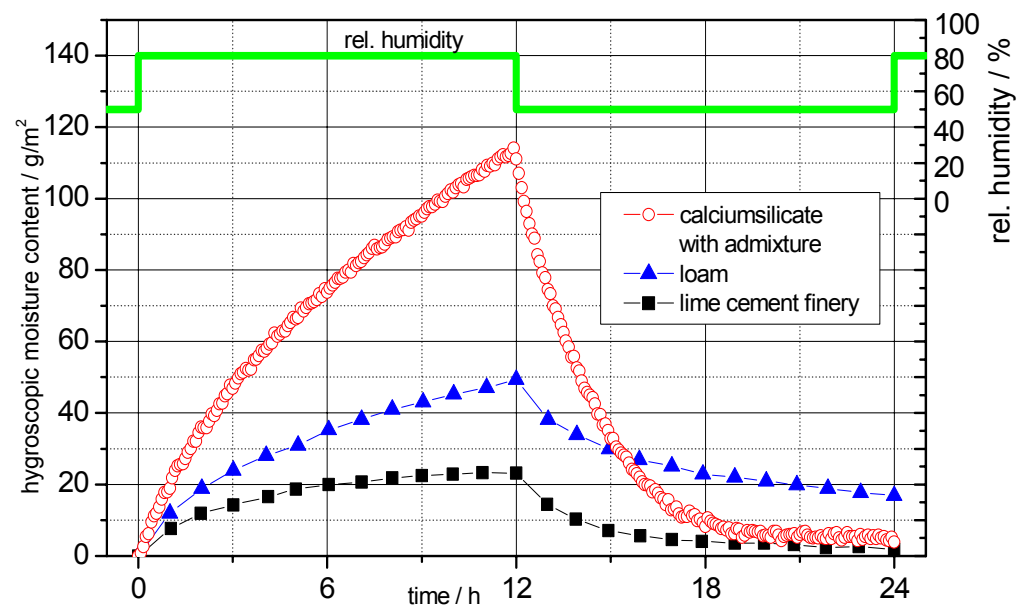

Figure 10: Determination of the time dependant hygroscopic properties of different materials in a climate test cabinet by means of step function time response [7, 8].

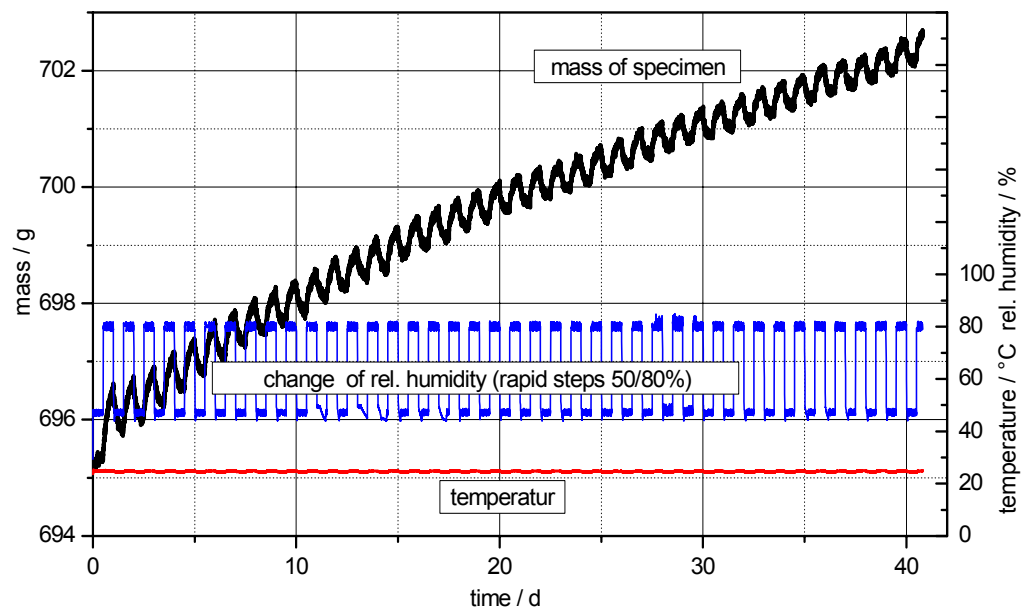

Figure 11: Long-time test acc. Fig. 10 in a climate test cabinet: special conditioning plaster, thickness: $10 \mathrm{~mm}$, area: $240 \mathrm{~mm} \times 115 \mathrm{~m}$.

\section{Conclusion}

Nowadays the energy balance and the hygrothermal performance of buildings is one of the current topics in the field of building physics. This paper has dealt with the coupled heat and moisture transfer at the adjacent area of surfaces of 
building envelopes influenced by indoor and outdoor climate components. By means of numerical simulation and laboratory work, including modulated sorptionisotherms by admixtures, the influence of internal surfaces of walls on the relative humidity of the indoor climate is demonstrated.

The effect of evaporation coolings on the energy transfer in wintertime and during the warm season requires the investigation of dewing and driving rain. It depends on the hygric parameters of coating of outside walls. A clear effect of infrared reflecting coatings could not be found, neither by means of laboratory experiments nor by in situ measurements. Moreover, it is shown in which way heat sources integrated in exterior walls could be a possible way of avoiding microbiological growth on building envelopes.

\section{Acknowledgement}

This work was partially supported by the Federal Ministry of Education and Research (BMBF), Germany, Project No. FKZ 1707703.

\section{References}

[1] Richtlinie 2002/91/EG des europäischen Parlaments und des Rates vom 16. Dez. 2002 über die Gesamtenergieeffizienz von Gebäuden (Umsetzung in Deutschland: EnEV 2007 vom 1.Okt. 2007, DIN V 18599 Energetische Bewertung von Gebäuden). Klimaschutzprogramm der Bundesrepublik Deutschland, Programm der Regierung vom 23. August 2007.

[2] ISO/DIS 12 571:Test method of adsorption/desorption efficiency for building materials to regulate an indoor humidity - Part 1: Response to humidity variation.

[3] Grunewald, J.: Diffusiver und konvektiver Stoff- und Energietransport kapillar-porösen Baustoffen. PhD thesis, TU Dresden, Germany, 1996

[4] Stopp, H; Strangfeld, P.: Energy saving and the hygrothermal performance of buildings. Conference proceedings, III. Latin American Conference on Comfort and Energy Efficiency in Buildings, Curitiba, Brazil, Nov. 2003.

[5] Stopp, H; Strangfeld, P.: Das hygrothermische Potenzial oberflächennaher Bereiche von außen- und Innenwänden. 12. Bauklimatisches Symposium Dresden, TU Dresden, Tagungsband 2, 29. -31. März 2007.

[6] DIN ISO 11 799: Information und Dokumentation - Anforderungen an dieAufbewahrung von Archiv- und Bibliotheksgut, Juni 2005.

[7] Lustig-Rössler, Ursula: Untersuchungen zum Feuchteverhalten von Lehm als Baustoff. Inaugural-Dissertation, Gesamthochschule Kassel, Universität. Kassel 1992.

[8] Japanese Industrial Standard JIS A 1470-1: Test method of adsorption/desorption efficiency for building materials to regulate an indoor humidity, 2002/08/20. 